\title{
Knowledge, Practice and Factors Associated with Pain Management for Adult Critical III Patients Among Nurses Working in Federal Hospitals of Addis Ababa Ethiopia 2020
}

\author{
Zewdu Gelaye Wondimagegn ${ }^{1}$, Hana Abera Hailemariam² ${ }^{2}$, Tesfahun Abye Meshesha ${ }^{3}$, \\ Solomon Olijra ${ }^{1}$ \\ ${ }^{1}$ Emergency Medicine and Critical Care Nursing, St. Paul hospital Millennium Medical College, Addis Ababa, Ethiopia \\ ${ }^{2}$ Maternal and Child Health Care Nursing, St. Paul Hospital Millennium Medical College, Addis Ababa, Ethiopia \\ ${ }^{3}$ Early Warning and Risk Management, Ethiopian Public Health Institute, Addis Ababa, Ethiopia
}

Email address:

zewdugelaye@gmail.com (Z. G. Wondimagegn)

To cite this article:

Zewdu Gelaye Wondimagegn, Hana Abera Hailemariam, Tesfahun Abye Meshesha, Solomon Olijra. Knowledge, Practice and Factors Associated with Pain Management for Adult Critical Ill Patients Among Nurses Working in Federal Hospitals of Addis Ababa Ethiopia 2020. American Journal of Clinical and Experimental Medicine. Vol. 9, No. 2, 2021, pp. 28-39. doi: 10.11648/j.ajcem.20210902.12

Received: February 2, 2021; Accepted: March 29, 2021; Published: April 16, 2021

\begin{abstract}
Background: Effective pain management requires precise knowledge and competent skills in practice. Nurses should have a solid foundation of pain knowledge and develop good practice pain management. Little is documented towards nurse's knowledge and practice of pain management among critical ill patients in the study area. Objective: To examine the level of knowledge, practice \& associated factors of nurses towards critically ill patients pain management at federal hospitals, Addis Ababa, Ethiopia September to October 2020. Method: A cross-sectional study design was conducted among nurses, who work at federal hospitals of Addis Ababa, Ethiopia from September 15 to October 15, 2020. All intensive care unit nurses was participated in the study. Data was collected by using self-administered structured questionnaire and entered into Epi info version 7 and imported to SPSS version 23.0 software for analysis. Associations was analyzed by using bivariate and multivariate logistic regression model. The findings were expressed with $95 \% \mathrm{CI}$ and odd ratio and P-value $<0.05$. Result: Knowledge of nurses towards pain management in the study area is $64.9 \%$. Among many factors contributed to the nurses' pain management knowledge in the Multivariate logistic regression: work load (AOR, 8.8, CI95\%, 1.45-53.39), training related to ICU (AOR, 10.8, CI95\%, 1.07-109.42), reading of guidelines (AOR, 10.11, CI95\%, 1.36-75.22), educational status (AOR, 16.38, CI95\%, 1.02-261.9), and practice of nurse towards pain management (AOR, 6.17, CI95\%; 1.38-27.56) were associated with knowledge of pain management. Nurses' practice of pain management in the study area is $56.5 \%$. Similarly having a training related to intensive care unit (AOR, 19.95, CI95\%, 3.03-130.9), and knowledge of nurse towards pain management (AOR, 5.30, CI95\%; 1.3-21.68) were significantly associated with practice of nurses on pain management. Conclusion and recommendation: The overall nurses' pain management knowledge in federal hospitals of Addis Ababa relative to Mekelle hospitals is good. Taking training, reading guidelines and level of education of nurses were significant predictors of nurse's knowledge. Receiving a training related to intensive care unit and having adequate knowledge of pain management were also associated with practice of pain management. Therefore, the need to give trainings and prepare guideline regarding pain assessment and management might escalate to address pain management among nurses.
\end{abstract}

Keywords: Knowledge, Practices, Factors, Pain Management, Critically Ill Patients

\section{Background}

Pain is an unpleasant sensory and emotional experience related to actual or potential damage. It develops the sensory experience of pain in the interaction between the nervous system and the environment [1] The processing of harmful stimuli and the resulting perception of pain involve the peripheral and central nervous systems [2]. It is a personal and subjective symptom that is influenced by age, gender, race, and psychosocial factors. Pain is one of the most common 
symptoms experienced by patients and approximately $79 \%$ of hospitalized patients suffer from it [3, 4].

Pain is a very serious and an enormous global health problem. Globally, it has been estimated that 1 in 5 adults suffer from pain and that another 1 in 10 adults is identified with chronic pain each year [5]. These patients experience pain from preexisting diseases, invasive procedures, or trauma. Critically ill patients normally are characterized to experience pain by tachycardia, tachypnea, anxiety, feeling discomfort [6].

In the critical care unit, moderate to severe pain has been identified as a common cause of patient stress. Pain is usually present in critically ill patients (CIPs) and its sign is associated both with the underlying disease that motivates their admission to the emergency room (ER) and the ICU. Patients' experience is also worse by unable to communicate, fear and anxiety $[7,8]$

This harms their overall status and is evidenced by changes in consciousness, movement, sleep, and endocrine, metabolic, gastrointestinal, and psychological functions [9]. Despite a lot of research done on pain management, it is still a significant problem for critically ill patients throughout their stay in the intensive care unit (ICU) [10].

Pain management practices are defined as a set of activities that should be provided by nurses to manage the patients' pain effectively [11]. These activities include assessing the patients' pain, providing appropriate nurse's interventions to relieve the patients' pain and reassessing the patients' pain after an intervention. Creating a suitable environment for critically ill patients is a universal goal for physicians and nurses because pain is one of the main problems that can minimize patients' relaxation [12].

Pain management is essential to the care of critically ill patients and it has been impeded by traditions and misconceptions, which have resulted in the suboptimal application of the currently available methods of pain control To be appropriately managed, pain must first be adequately assessed. Although pain is difficult to assess in non-verbal patients, a combination of physiologic and behavioral indicators should be helpful. The use of a pain flow sheet can facilitate the documentation of pain assessment and reassessment thereby improving the effectiveness of pain control strategies [13].

Pain management is an integral part of HCP practices. Therefore HCP must be well equipped with knowledge and practice to manage pain [14]. Nurses have stayed $24 \mathrm{hrs}$. along with the patient, therefore, they are responsible to asses and manage pain by applying the different methods of management i.e. pharmacological therapy like giving analgesia or sedative and none pharmacological therapy like massaging and applying cold compressor [15].

Inappropriate pain assessment and the resulting inadequate treatment of pain in critically ill adults can have significant physiological and psychological problems. Under-diagnosed pain has been linked to many adverse outcomes including increased infection rate, prolonged mechanical ventilation, hemodynamic derangements, delirium, and compromised immunity [16, 17].

In critically ill patients effective management of pain is vital to ensure the best possible clinical results and prevent unnecessary stay in hospitals and suffer from pain [18, 19]. This study aims to assess the knowledge, practice, \&associated factors of nurses towards pain management in the intensive care unit.

Prevalence of pain is high in developing countries due to late diagnosis of disease and major impediments to opioid access. In case of life-threatening damage or illness, pain and its treatment are forgotten, or under-appreciated by the health care providers [20]. Pain management has been left largely unaddressed due to factors like limited resources, inadequate training, as well as cultural diversity and language barriers which made sick and injured patients not to receive basic pain care [21]. Overlooking patients' pain leads to many consequences and complications for both the patients and the healthcare organization [22]. An estimated precise evaluation of pain was made in less than $40 \%$ of overall mechanically ventilated patients [23].

The pain management practices in any healthcare system were affected by three major barriers which include organizational barriers, healthcare providers' barrier and patients' barriers [24]. Among the most common heath, system-related obstacles are lack of guidelines and protocols for pain assessment and management, logistical consumables related to timely analgesic administration, inadequate quality improvement monitoring and evaluation, and a lack of accountability for poorly managed pain [25].

Healthcare providers' related barriers, such as inadequate knowledge of the types and appropriate dosages of analgesics regarding the pain assessment and management principles contribute considerably to suboptimal pain management among critically ill patients [26]. Other healthcare providers' barrier includes the inability to assess and acknowledge the existence of pain, giving low priority to pain management, and fear of triggering opioid addiction [27].

Personal and cultural biases and communication difficulties between the patient and the healthcare team are other provider-patient related barriers to pain management [28]. Patient-related factors may also contribute to ineffective pain management. The effects of sedation or neurologic compromise may prevent the verbal, behavioral, or physical expression of pain. Furthermore, patients may think that pain should be tolerated, feel that requests for pain medications are troublesome, or experience communication fatigue [29]. Another study has identified several barriers to adequate pain management in ICU such as sociocultural factors, the concerns regarding addiction, distrust of the health care professional and the lack of knowledge [30].

Intensive Care Unit patient's alertness is affected by the administration of sedatives and/or painkillers and disease itself progression [31]. Thus most ICU patients may have difficulty communicating the experience of pain and describing the intensity of pain, making it difficult or 
impossible for medical professionals to evaluate their pain accurately; however, nurses administer only $23-43 \%$ of analgesics ordered [32]. Despite the fact pain management has become a national priority in recent years, pain continues to be misinterpreted, poorly assessed, and undertreated in the critical care unit and many other healthcare settings [33].

Pain management problems have not been addressed adequately by critical care nurses and also knowledge deficits regarding pain assessment and management principles contribute significantly to suboptimal pain controlling among critically ill patients [34]. Having adequate knowledge and good practice is important for nurses to manage patient's pain and related problems to decreasing anxiety and length of stay in the intensive care unit [35].

Despite numerous studies about factors associated with pain management that have been explored, little is known about factors related to knowledge and practice towards pain management in critically ill patients in Ethiopia [36] Research related to practices regarding pain assessment in hospitalized critically ill patients also remains limited [37]. To improve the quality of healthcare and outcomes, there is a need to assess the level of knowledge, practices and work experience to pain assessment and management among nurses as well as barriers to practices [38]. Therefore this study was to assess knowledge, practice and factors associated with pain assessment and management for hospitalized adult critically ill patients in the Intensive Care Unit among nurses working in federal hospitals of Addis Ababa, Ethiopia, 2020.

As many studies show, pain is unrecognized and undertreated by any health care professional all over the world. Thus, managing pain properly is the only option that can prevent ICU patients from an unnecessary stay in hospitals and suffer from pain. Numerous studies have been performed concerning knowledge practice and factors associated with pain management for critical patients in other countries particularly in the developed world. As far as the investigator knowledge is concerned there is a limited study were carried out in Ethiopia regarding on knowledge, practice and associated factors of pain management, Therefore the finding will contributing in minimization of gaps or escalating the knowledge and practice of nurses by providing a recommendation on the level of knowledge and practice of nurses towards pain management on critically ill patients and associated factors. Moreover, it would be a starting point information for hospitals and will offer insight for hospitals and stakeholders on training toward knowledge and practice of nurses for critically ill patient's pain management. Furthermore; it will provide baseline information to any interested researcher to conduct further research on this area related knowledge practice and factors associated with pain management in ICU. The main reason that elicits the investigators to undertake this study is to decrease pain complications in ICU.

\section{Objectives}

\subsection{General Objective}

To assess knowledge, practice and factors associated with pain management for hospitalized adult critically ill patients in the Intensive Care Unit among nurses working in federal hospitals of Addis Ababa, Ethiopia, 2020.

\subsection{Specific Objectives}

To assess knowledge of nurses working in federal hospitals towards pain management in hospitalized adult critically ill patients in the intensive care unit, Addis Ababa, Ethiopia, 2020 .

To assess the practice of nurses working in federal hospitals towards pain management in hospitalized adult critically ill patients in the intensive care unit, Addis Ababa, Ethiopia, 2020.

To identify factors associated with pain management among nurses for hospitalized adult critically ill patients in the intensive care unit in federal hospitals of Addis Ababa, Ethiopia, 2020.

\section{Methods and Materials}

\subsection{Study Area}

The study was conducted at Federal administered hospitals in Addis Ababa, which is a capital city of Ethiopia \& setting for the African Union (AU). It has a population size of $3,048,631$ of whom $1,595,968$ were females and the rest1, 452,663 were males. The city is divided into 10 sub-cities. The city is located at the heart of the country; at an altitude ranging from 2,100 meters at Akaki in the south to 3,000 meters at Entoto Hill in the North. The city has 49 hospitals.

Thirteen are public hospitals. Of these public (governmental) hospitals six of them are under Addis Ababa city administration namely, Yekatit 12 hospital, Mimili the second, Ras Desta, Zewuditu memorial hospital, Gandhi Memorial hospital, and Tirunesh general hospital. The other five hospitals are administered under the federal ministry of health of Ethiopia including Tikur Anbessa General Specialized Hospital, St. Paul hospital millennium medical college, Amanuel psychiatric hospital, Alert hospital, and St. Peter are under these group. The rest two hospitals are under the defense ministry of Ethiopia i.e., army and defense hospitals. Thirty-six of the city's hospitals are private. Furthermore, the city has 51 health centers and 700 different level private clinics [42]. Total nurse who are working in sent Paulo's 1248 hospital, in abet hospitals 322, in black line specialized hospital 915, in alert 390, in sent peter 228 and in yeka kotebe hospitals 158 nurses this data taken from human resource of each hospitals.

\subsection{Study Design and Period}

Cross-sectional study was employed. The study was conducted in federally administered hospitals in Addis Ababa 
from September 15 - October 15, 2020.

\subsection{Study Population}

The study population was all ICU staff nurses who are available during data collection time and working in adult intensive care unit for more than 6 months in Federal hospitals of Addis Ababa, Ethiopia

\subsection{Inclusion and Exclusion Criteria}

Inclusion criteria

Staff nurses' who were working in ICU for greater than six months and available during data collection time.

Exclusion criteria

Staff nurses who are not cooperating to fill the administered questionnaire were excluded. Staff nurses who are critically ill during data collection.

\subsection{Sample Size and Sampling Technique}

There are a total of 6 federal Hospitals in Addis Ababa Ethiopia. All six federal hospitals were included purposively considering the chance of getting highly critically ill patients in the intensive care units. All 208 ICU staff nurses working in federal hospitals of Addis Ababa were included in the study.

\subsection{Study Variables}

Dependent variable

Knowledge and practice of pain management

Independent Variables

Demographic and professional characteristics (Age, Gender, marital status, Experience, Working area).

Institutional factors (workload, lack of pain management tools, availability of pain drug, lack guidelines).

\subsection{Data Collection Tools and Procedures}

The self-administered questionnaire was used which was adapted from the previous different studies to address both dependent and independent variables. The tools consisted of questioners that were prepared in the English version. There were three data collectors and one supervisor. During data collection, the supervisor had monitored the data collection process by checking the completeness of the data and take the necessary correction on the site of data collection when any problem happened.

\subsection{Data Quality Assurance}

To assure the quality of the data; one-day training were given for 3 data collectors (all Bsc holders) and 1 supervisor (experienced Bsc holder) before data collection. The questionnaire was carefully designed and has an English version. A pretest was done two weeks before the study in Ykatit 12 Hospital on $10(5 \%)$ of the sample. Based on the pretest, a questionnaire was corrected to ensure clarity, wording, and logical sequence and skip patterns. The supervisor had checked the data for its completeness during data entry and the cleaning process. Completeness and consistency of the variable during data entry and analysis were checked by using frequency distribution, cross tabulation, sorting in ascending and descending order.

\subsection{Data Processing and Analysis}

The collected data was entered into Epi info version 7.1 for data entry, recording, and cleaning. The analysis was done with SPSS version 23. Descriptive statistics such as frequencies, proportions, means, and medians were calculated. Variables that were considered as significantly associated with $\mathrm{p}$-value $<0.05$ using bivariate analysis and was entered into the multivariable analysis logistic regression model. Finally, the variables which had significant association was identified based on the odds ratio (OR), with $95 \%$ CI. The findings were expressed with 95\% CIs and a significant variable was declared at $\mathrm{p}<0.05$.

\section{Result}

Socio-demographic characteristics

In this study, 193 participants were included in the analysis with a response rate of $92.79 \%$. The mean age of participants was 27.99 with a standard deviation of \pm 4.36 . Majority of the participants were female $112(58 \%)$ and $81(42 \%)$ were males. From the respondents $76.7 \%$ were with the age of range of 21-30 followed by 31-40 age range with $21.8 \%$. About 117 (60.6\%) were single participants and 73 (37.8\%) were married. Concerning the experience of nurses in the intensive care unit (ICU), only $6(3.1 \%)$ of participants had an experience of $>11$ years but majority $(83,(43 \%))$ of participants had an experience of $<2$ years. Most (181, (93.8) of participants are degree holders and the rest 12 (6.2\%) were diploma nurses. Majority of nurses were working by shifts $164(85 \%)$. From the respondents $154(79.8 \%), 30(15.5 \%)$ and $9(4.7 \%)$ were working in medical, the surgical and in the transplant ICU respectively. The majority of the respondents were staff nurses 186 (96.4) the rest were coordinators nurses $7(3.6 \%)$. The majority of nurses $(179,(92.7 \%)$ believed that there is work load in the working unit.

Knowledge of nurses towards pain management

Most of knowledge assessing questions on pain management were answered by participant nurses hold above the mean score $(62.5 \%)$ whereas the rest answer below the mean core $(37.5 \%)$. The rate of correct answers ranged from $23.3 \%$ (for the worst- answered item) to $78.2 \%$ (for the bestanswered item).

The most frequently answered questioner $78.2 \%$ by the participants with the right response were question number 205 "Is combining analgesics result in better pain control with fewer side effects than using a single analgesic agent?" was frequently answered by most participants with right response of $78.2 \%$ followed by question number 204 "Does respiratory depression rarely occurs in patients who have been receiving stable dose of opioid over a month?" with a right response of $69.9 \%$. But the question 201 "Are vital signs are always reliable indicators of patients pain intensity?" are 
poorly answered with only $23.3 \%$ correct response followed by question number 13 "If the source of the patient's pain is unknown; opioids should not be used during the pain evaluation period?" with right responses of only $30.1 \%$.

Using independent sample t-test, there was no significant difference between males (mean 1.30) and females (mean
1.31) in the mean score of nurses' knowledges towards pain management with $p$ value 0.81 . In one-way ANOVA analysis, there was no significant difference between marital status $(p=0.913)$, Intensive care unit/ward $(p=0.655)$, work experience $(\mathrm{p}=0.609)$, and age $(\mathrm{p}=0.333)$ as regards the mean score of nurses' knowledge towards pain management.

Table 1. Socio-demographic characteristics of nurses working in all federal hospitals of Addis Ababa, Ethiopia, 2020.

\begin{tabular}{|c|c|c|c|c|}
\hline S. No & Variable & Response & Frequency & Percent (\%) \\
\hline \multirow{2}{*}{1} & \multirow{2}{*}{ Gender } & Male & 81 & 42 \\
\hline & & Female & 112 & 58 \\
\hline \multirow{3}{*}{2} & \multirow{3}{*}{ Marital status } & Single & 117 & 60.6 \\
\hline & & Married & 73 & 37.8 \\
\hline & & Divorced & 3 & 1.6 \\
\hline \multirow{4}{*}{3} & \multirow{4}{*}{ Experience in the ICU } & $<2$ years & 83 & 43 \\
\hline & & 2-5years & 82 & 42.5 \\
\hline & & 6-10years & 22 & 11.4 \\
\hline & & $>11$ years & 6 & 3.1 \\
\hline \multirow{2}{*}{4} & \multirow{2}{*}{ Educational level } & Degree & 181 & 93.8 \\
\hline & & Diploma & 12 & 6.2 \\
\hline \multirow{3}{*}{5} & \multirow{3}{*}{ Shift of work } & Days only & 20 & 10.4 \\
\hline & & Nights only & 9 & 4.7 \\
\hline & & Rotating shift & 164 & 85 \\
\hline \multirow{3}{*}{6} & \multirow{3}{*}{ Working area } & Medical ICU & 154 & 79.8 \\
\hline & & Surgical ICU & 30 & 15.5 \\
\hline & & Transplant ICU & 9 & 4.7 \\
\hline \multirow{4}{*}{7} & \multirow{4}{*}{ Age category } & $21-30$ & 148 & 76.7 \\
\hline & & $31-40$ & 42 & 21.8 \\
\hline & & $41-50$ & 1 & .5 \\
\hline & & $50+$ & 2 & 1 \\
\hline \multirow{2}{*}{8} & \multirow{2}{*}{ Position } & coordinator nurse & 7 & 3.6 \\
\hline & & Staff nurse & 186 & 96.4 \\
\hline \multirow{2}{*}{9} & \multirow{2}{*}{ Work load } & Yes & 179 & 92.7 \\
\hline & & No & 14 & 7.3 \\
\hline
\end{tabular}

Table 2. Knowledge of nurses on pain management in all federal hospitals of Addis Ababa, Ethiopia, 2020.

\begin{tabular}{|c|c|c|c|c|c|}
\hline \multirow[t]{2}{*}{ S. No } & \multirow[t]{2}{*}{ Variable } & \multicolumn{2}{|c|}{$\begin{array}{l}\text { Response in } \\
\text { number }\end{array}$} & \multicolumn{2}{|c|}{$\begin{array}{l}\text { Response in } \\
\text { Percent }\end{array}$} \\
\hline & & Yes & No & Yes & No \\
\hline 201 & Vital signs are reliable indicators of patient's pain intensity. & 148 & 45 & 76.7 & 23.3 \\
\hline 202 & Patients who can be distracted from pain don't have severe pain. & 88 & 105 & 45.6 & 54.4 \\
\hline 203 & Patients may sleep despite severe pain. & 76 & 117 & 39.4 & 60.6 \\
\hline 204 & $\begin{array}{l}\text { Respiratory depression occurs in patients who have been receiving stable dose of opioid over a } \\
\text { month. }\end{array}$ & 135 & 58 & 69.9 & 30.1 \\
\hline 205 & $\begin{array}{l}\text { Combining analgesics can result better pain control with fewer side effects than using a single } \\
\text { analgesic agent. }\end{array}$ & 151 & 42 & 78.2 & 21.8 \\
\hline 206 & Promethazine and hydroxyzine are reliable potentiates of opioid analgesics. & 102 & 91 & 52.8 & 47.2 \\
\hline 207 & Opioids should not be used in patients with a history of substance abuse. & 92 & 101 & 47.7 & 52.3 \\
\hline 208 & Morphine have a dose ceiling effect & 133 & 60 & 68.9 & 31.1 \\
\hline 209 & Elderly patient can tolerate opioids. & 91 & 102 & 47.2 & 52.8 \\
\hline 210 & Patients can be encourage to endure as much pain as possible before using an opioid. & 110 & 83 & 57.0 & 43.0 \\
\hline 211 & Do you adjust after an initial doses of opioid analgesic & 145 & 48 & 75.1 & 24.9 \\
\hline 212 & Gave sterile water (placebo) for the patient's to determine if the pain is real & 86 & 107 & 44.6 & 55.4 \\
\hline 213 & $\begin{array}{l}\text { If the source of the patient's pain is unknown; opioids should not be used during the pain } \\
\text { evaluation period }\end{array}$ & 135 & 58 & 69.9 & 30.1 \\
\hline 214 & Anticonvulsant drugs produce optimal pain relief after a single dose & 92 & 101 & 47.7 & 52.3 \\
\hline 215 & Benzodiazepines are not effective pain relievers unless the pain is due to muscle spasm & 106 & 87 & 54.9 & 45.1 \\
\hline 216 & $\begin{array}{l}\text { Narcotic opioid addiction is defined as a chronic neurobiological diseases characterized by } \\
\text { behaviors that include; impaired control over drug use, compulsive use, continued use despite } \\
\text { harm, and craving }\end{array}$ & 130 & 63 & 67.4 & 32.6 \\
\hline
\end{tabular}




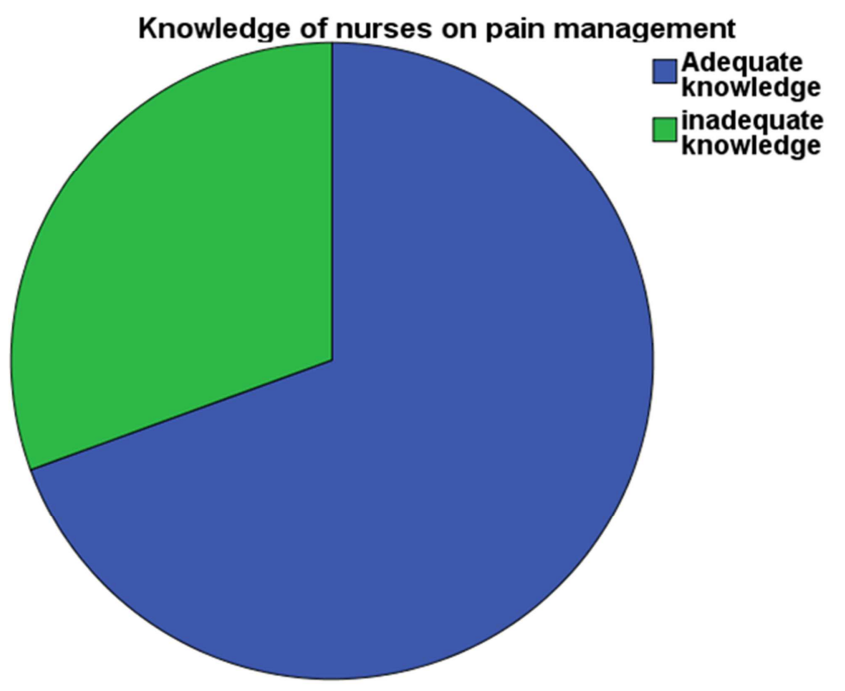

Figure 1. Knowledge of nurses on pain management who works in all federal hospitals of Addis Ababa, Ethiopia, 2020.

Regarding the knowledge of participant nurses on pain management; most of them $(134,(64.9 \%))$ have an adequate knowledge of pain management. The mean score of total correct answers was 9.11 with a Standard deviation of 2.97
(9.11 \pm 2.97$)$ out of a possible 16 knowledge question items ranging from a minimum of 4 and maximum of 16 correct answers.

Practice of nurses towards pain assessment and management

Among the nine practice assessing questions; Almost half (5/9) of the practiced questions were answered by the participants for practicing in pain management above the mean score. Majority of participants (89.1\%) had documented outcomes after assessing patient's pain and also $91.6 \%$ of nurses had given opioid analgesics to patients with severe pain of abrupt onset. About 87 (45.1\%) of nurses had used pain assessment tools to assess patient's status whenever necessary and $27(14 \%)$ of nurses had used pain assessment tools once every shift while the standard was to assess the pain of patients every hour with the help of pain assessment tools. Among the participated nurses; $50.8 \%$ of them use universal pain assessment tools, 53.9\% Facial expression tools and the rest $23.8 \%$ use Verbal rating scale for assessing critically ill patient's pain and among this $89.1 \%$ documented outcomes after assessing patient's pain.

Table 3. Practice of nurses towards pain management in all federal hospitals of Addis Ababa, Ethiopia, 2020.

\begin{tabular}{|c|c|c|c|c|c|}
\hline S. No & Variable & & Response & $\begin{array}{l}\text { Response in } \\
\text { number }\end{array}$ & $\begin{array}{l}\text { Response in } \\
\text { Percent }\end{array}$ \\
\hline \multirow{2}{*}{301} & \multirow{2}{*}{\multicolumn{2}{|c|}{ Using pain assessment tools }} & Yes & 167 & 86.5 \\
\hline & & & No & 26 & 13.5 \\
\hline \multirow{3}{*}{302} & \multirow{3}{*}{\multicolumn{2}{|c|}{ Frequency of using pain assessment tools }} & Always & 72 & 37.3 \\
\hline & & & Frequently & 47 & 24.4 \\
\hline & & & Occasionally & 74 & 38.3 \\
\hline \multirow{6}{*}{303} & \multirow{6}{*}{ Name of tools } & \multirow{2}{*}{$\begin{array}{l}\text { Universal pain } \\
\text { assessment tools }\end{array}$} & Yes & 98 & 50.8 \\
\hline & & & No & 95 & 49.2 \\
\hline & & \multirow{2}{*}{ Facial expression tools } & Yes & 104 & 53.9 \\
\hline & & & No & 89 & 46.1 \\
\hline & & \multirow{2}{*}{ Verbal rating scale } & Yes & 46 & 23.8 \\
\hline & & & No & 147 & 76.2 \\
\hline \multirow{6}{*}{304} & \multirow{2}{*}{\multicolumn{2}{|c|}{ Observing the patient }} & Yes & 142 & 73.6 \\
\hline & & & No & 51 & 26.4 \\
\hline & If Not use, other optional & \multirow{2}{*}{ Estimating by experience } & Yes & 63 & 32.6 \\
\hline & methods & & No & 130 & 67.4 \\
\hline & & \multirow{2}{*}{ Using water for injection } & Yes & 46 & 23.8 \\
\hline & & & No & 147 & 76.2 \\
\hline \multirow{2}{*}{305} & \multirow{2}{*}{\multicolumn{2}{|c|}{ Document out comes after assessing patients' pain. }} & Yes & 172 & 89.1 \\
\hline & & & No & 21 & 10.9 \\
\hline \multirow{5}{*}{306} & \multirow{5}{*}{\multicolumn{2}{|c|}{$\begin{array}{l}\text { Frequency of assessing pain for a patient who can } \\
\text { report pain. }\end{array}$}} & Whenever necessary & 87 & 45.1 \\
\hline & & & Once every shift & 27 & 14 \\
\hline & & & 4-8 hour & 10 & 5.2 \\
\hline & & & 1-4 hour & 47 & 24.4 \\
\hline & & & $<1$ hour & 8 & 4.1 \\
\hline \multirow{2}{*}{307} & \multirow{2}{*}{\multicolumn{2}{|c|}{$\begin{array}{l}\text { Discussing pain ratings and management during nurse- } \\
\text { to-nurse report }\end{array}$}} & Yes & 166 & 86.0 \\
\hline & & & No & 27 & 14.0 \\
\hline \multirow{2}{*}{308} & \multirow{2}{*}{\multicolumn{2}{|c|}{ Assessing pain before initiating management }} & Yes & 182 & 94.3 \\
\hline & & & No & 10 & 5.2 \\
\hline \multirow{2}{*}{309} & \multirow{2}{*}{\multicolumn{2}{|c|}{$\begin{array}{l}\text { Opioid analgesics should be given to patients with } \\
\text { severe pain of abrupt onset }\end{array}$}} & Intramuscular & 17 & 8.8 \\
\hline & & & Intravenous & 176 & 91.2 \\
\hline
\end{tabular}




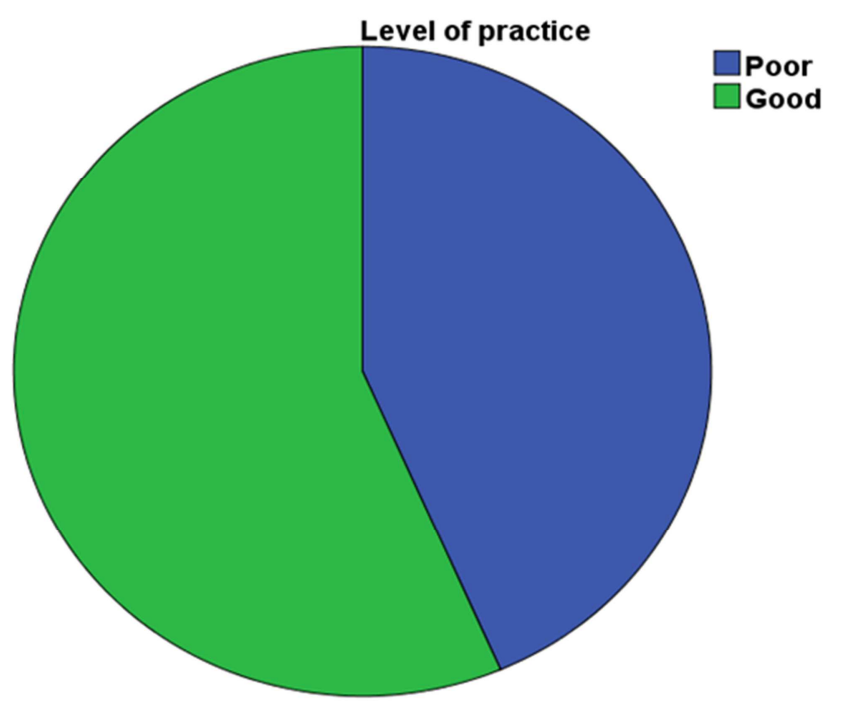

Figure 2. Level of practice of nurses on pain management who works in all federal hospitals of Addis Ababa, Ethiopia, 2020.

Regarding the level of practice of participant nurses on pain management; more than half of participants have good practice
$(56.5 \%)$ of pain management. The mean score of total correct answers was 5.62 with a Standard deviation of 1.689 $(5.62 \pm 1.689)$ out of a possible 9 practice question items ranging from a minimum of 3 and maximum of 9 correct answers. The rate of correct answers ranged from $4.1 \%$ (for the worst- answered item) to $94.3 \%$ (for the best- answered item).

Factors associated with Knowledge of nurses on pain management

Around $148(76.7 \%)$ of nurses have pain management protocols/guide lines in their hospital and 145 (75.1\%) had a pain assessment tools while $93(48.2 \%)$ have not yet used either of the two. From the participants; 161 (83.4\%) of participant nurses believe that a patient's inability to communicate can affect pain assessment. Majority 116 $(61.7 \%)$ of nurses didn't get a training but only 74 (38.3\%) of nurses had got a formal training related to ICU pain assessment and management during the last two years. The participant nurses who thinks that sedatives can affect pain management accounts $162(83.9 \%)$ and the rest 31 (16.1\%) didn't think so.

Table 4. Description of factors related with Knowledge of nurses towards pain assessment and management in all federal hospitals of Addis Ababa, Ethiopia, 2020

\begin{tabular}{|c|c|c|c|c|}
\hline S. No & Variable & Response & Response in number & Response in Percent \\
\hline \multirow{2}{*}{401} & \multirow{2}{*}{ Having protocols/guide lines in the hospital } & Yes & 148 & 76.7 \\
\hline & & No & 45 & 23.3 \\
\hline \multirow{2}{*}{402} & \multirow{2}{*}{ Have a pain assessment tool } & Yes & 145 & 75.1 \\
\hline & & No & 48 & 24.9 \\
\hline \multirow[b]{2}{*}{403} & \multirow[b]{2}{*}{ Frequency of reading guidelines } & Always & 51 & 26.4 \\
\hline & & Monthly & 27 & 14.0 \\
\hline \multirow{2}{*}{404} & \multirow{2}{*}{$\begin{array}{l}\text { Patient's inability to communicate could affect pain } \\
\text { assessment }\end{array}$} & yes & 161 & 83.4 \\
\hline & & No & 32 & 16.6 \\
\hline \multirow{2}{*}{405} & \multirow{2}{*}{ Availability of morphine in the stock } & Yes & 85 & 44.0 \\
\hline & & No & 108 & 56.0 \\
\hline \multirow{2}{*}{406} & \multirow{2}{*}{ Received training related to ICU } & Yes & 74 & 38.3 \\
\hline & & No & 119 & 61.7 \\
\hline \multirow{2}{*}{407} & \multirow{2}{*}{ Satisfaction with the training } & Yes & 45 & 60.8 \\
\hline & & No & 29 & 39.2 \\
\hline \multirow{2}{*}{408} & \multirow{2}{*}{ Sedative can affect Pain management } & Yes & 162 & 83.9 \\
\hline & & No & 31 & 16.1 \\
\hline
\end{tabular}

Variables which have a significant association $(\mathrm{P}<0.05)$ with the level of knowledge in the bivariate logistic regression are; having a work load with and odd ratio of (COR, 10.3, CI 95\%, 4.79-22.19), working in the night shift with (COR, 4.09, CI95\%, 1.57-10.67), not receiving a training related to ICU pain management during the last two years with (COR, 16.9, CI95\%, 5.81-49.47) and working in the night shift with an odd ration of (COR, 4.09, CI95\%, 1.57-10.67). In addition to this; reading guidelines occasionally with (COR, 10.3, CI95\%, 2.58-41.1), being a diploma over degree (COR, 2.47, CI95\%, 1.1-5.52) and nurses who have a good practice are twice more likely to have an adequate knowledge (COR, 11.8, CI95\%; 5.56-

\subsection{6).}

In multiple variable analysis; having a work load (AOR, $8.8(95 \% \mathrm{CI}$; $1.45-53.39)$, have 9 times more likely to have adequate knowledge of pain management in the ICU. Receiving a training on pain management (AOR, 10.8 (95\%CI; 1.07-109.42), also have 11 times more likely to have adequate knowledge of pain management. Reading guidelines occasionally (AOR, 10.11, 95\%CI, 1.36-75.22), could be 10 times more likely to have inadequate knowledge of pain management. Level of education (AOR, 16.38 95\%CI, 1.02-261.90), and level of practice (AOR, 6.17 95\%CI, 1.3827.56) have a significant association with level of knowledge. 
Table 5. Bivariate and multivariate logistic regression on factors associated with knowledge of nurses towards pain management in all federal hospitals of Addis Ababa, Ethiopia, 2020.

\begin{tabular}{|c|c|c|c|c|c|c|c|}
\hline \multirow{2}{*}{$\begin{array}{ll}\text { S. } \\
\text { No }\end{array}$} & \multirow{2}{*}{ Variable } & \multirow{2}{*}{ Response } & \multicolumn{2}{|l|}{ Knowledge } & \multicolumn{3}{|l|}{ OR $(95 \%$ CI) } \\
\hline & & & Adequate & Inadequate & COR & AOR & Pvalue \\
\hline \multirow{3}{*}{1} & \multirow{3}{*}{ Work load } & Yes & $121(81.2 \%)$ & $28(18.8 \%)$ & 1 & 1 & 1 \\
\hline & & No & $13(29.5 \%)$ & $31(70.5 \%)$ & $10.3(4.79-22.19)^{*}$ & $8.8(1.45-53.39)^{* *}$ & .018 \\
\hline & & Days only & $8(40 \%)$ & $12(60 \%)$ & 1 & 1 & \\
\hline \multirow[t]{2}{*}{2} & \multirow[t]{2}{*}{ Working Shift } & Nights only & $6(66.7 \%)$ & $3(33.3 \%)$ & $4.09(1.57-10.67)^{*}$ & $4.8(.7-33.86)$ & .111 \\
\hline & & Rotating shift & $120(73.2 \%)$ & $44(26.8 \%)$ & $1.36(.33-5.69)$ & $.87(.02-33.69)$ & .939 \\
\hline \multirow{2}{*}{3} & \multirow{2}{*}{$\begin{array}{l}\text { Received training related } \\
\text { with ICU }\end{array}$} & Yes & $74(94.9 \%)$ & $4(5.1 \%)$ & 1 & 1 & \\
\hline & & No & $60(52.2 \%)$ & $55(47.8 \%)$ & $16.9(5.81-49.47) *$ & $10.8(1.07-109.42)^{* *}$ & .044 \\
\hline \multirow{3}{*}{4} & \multirow{3}{*}{$\begin{array}{l}\text { Frequency of reading } \\
\text { guidelines }\end{array}$} & Always & $38(70.4 \%)$ & $16(29.6 \%)$ & 1 & 1 & \\
\hline & & Frequently & $19(70.4 \%)$ & $8(29.6 \%)$ & $1(.36-2.75)$ & $2.92(.53-16.15)$ & .22 \\
\hline & & Occasionally & $3(18.8 \%)$ & $13(81.3 \%)$ & $10.3(2.58-41.1) *$ & $10.11(1.36-75.22)^{* *}$ & .024 \\
\hline \multirow{2}{*}{5} & \multirow{2}{*}{ level of education } & Degree & $119(72.6 \%)$ & $45(27.4 \%)$ & 1 & 1 & \\
\hline & & Diploma & $15(51.7 \%)$ & $14(48.3 \%)$ & $2.47(1.1-5.52) *$ & $16.38(1.02-261.90)^{* *}$ & .048 \\
\hline \multirow[b]{2}{*}{6} & \multirow{2}{*}{ Practice } & Good & $98(89.9 \%)$ & $11(10.1 \%)$ & 1 & 1 & \\
\hline & & poor & $36(42.9 \%)$ & $48(57.1 \%)$ & $11.8(5.56-25.36) *$ & $6.17(1.38-27.56)^{* *}$ & .017 \\
\hline
\end{tabular}

${ }^{*} \mathrm{p}<0.05$, CI- $95 \%$ (Confidence Interval), COD- crude odds ratio, AOD-adjusted odds ratio

** Remained statistically significant $(\mathrm{p}<0.05)$ in adjusted odds ratio

$P$ value is for adjusted odd ratio

Factors associated with practice of nurses on pain assessment and management

Variables which have a significant association $(\mathrm{P}<0.05)$ with the level of practice in the bivariate logistic regression are; having a work load with an odd ratio of (COR, 3.77, CI $95 \%, 1.84-7.72)$, working in the night shift with (COR, 2.69, CI95\%, 1.02-7.09), and not receiving a training related to ICU pain management during the last two years with (COR, 9.21, CI95\%, 4.48-18.95). In addition to this; reading guidelines occasionally with (COR, 8.57, CI95\%, 2.07-
35.52), and frequently with (COR, 6.0 (95\%CI; 1.69-21.26), and nurses who have a good knowledge are more likely to have an adequate knowledge (COR, 11.88, CI95\%; 5.5625.36).

In multiple variable analysis; receiving a training on pain management (AOR, 19.95 (95\%CI; 3.03-130.9), have 20 times more likely to have good practice of pain management and having adequate knowledge (AOR, 5.3 95\%CI, 1.3020.68) have 5 times more likely to have good practice.

Table 6. Bivariate and multivariate logistic regression of factors affecting practice of nurses towards pain management in all federal hospitals of Addis Ababa, Ethiopia, 2020

\begin{tabular}{|c|c|c|c|c|c|c|c|}
\hline \multirow{2}{*}{$\begin{array}{l}\text { S. } \\
\text { No }\end{array}$} & \multirow{2}{*}{ Variable } & \multirow{2}{*}{ Response } & \multicolumn{2}{|l|}{ Practice } & \multicolumn{3}{|l|}{ OR $(95 \%$ CI $)$} \\
\hline & & & Good & Poor & COR & AOR & P value \\
\hline \multirow[b]{2}{*}{1} & \multirow{2}{*}{ Work load } & Yes & $95(63.8 \%)$ & $54(36.2 \%)$ & $3.77(1.84-7.72)^{*}$ & $.307(.04-2.16)$ & \\
\hline & & No & $14(31.8 \%)$ & $30(68.2 \%)$ & 1 & 1 & \\
\hline \multirow{3}{*}{2} & \multirow{3}{*}{ Working Shift } & Days only & $7(35.0 \%)$ & $13(65.0 \%)$ & 1 & 1 & \\
\hline & & Nights only & $5(55.6 \%)$ & $4(44.4 \%)$ & $2.69(1.02-7.09)^{*}$ & 1.08. $(21-5.53)$ & \\
\hline & & Rotating shift & $97(59.1 \%)$ & $67(40.9 \%)$ & $2.32(.47-11.55)$ & $1.465(.08-26.741)$ & \\
\hline \multirow{2}{*}{3} & \multirow{3}{*}{$\begin{array}{l}\text { Received training related with } \\
\text { ICU }\end{array}$} & Yes & $66(84.6 \%)$ & $12(15.4 \%)$ & 1 & 1 & \\
\hline & & No & $43(37.4 \%)$ & $72(62.6 \%)$ & $9.21(4.48-18.95)^{*}$ & $19.95(3.034-130.9)^{* *}$ & .002 \\
\hline \multirow{3}{*}{4} & & Always & $36(66.7 \%)$ & $18(33.3 \%)$ & 1 & 1 & \\
\hline & \multirow[t]{2}{*}{ Frequency of reading guidelines } & Frequently & $20(74.1 \%)$ & $7(25.9 \%)$ & 6. $(1.69-21.26)^{*}$ & $1.46(.26-8.34)$ & \\
\hline & & Occasionally & $4(25.0 \%)$ & $4(25.0 \%)$ & $8.57(2.07-35.52)^{*}$ & $2.41(.40-14.46)$ & \\
\hline \multirow{2}{*}{5} & \multirow{2}{*}{ level of education } & Degree & $94(57.3 \%)$ & $70(42.7 \%)$ & 1 & 1 & \\
\hline & & Diploma & $15(51.7 \%)$ & $14(48.3 \%)$ & $.79(.36-1.76)$ & $.31(.04-2.16)$ & \\
\hline \multirow{2}{*}{6} & \multirow{2}{*}{ Knowledge } & Adequate & $98(73.1 \%)$ & $36(26.9 \%)$ & 1 & 1 & \\
\hline & & Inadequate & $84(43.5 \%)$ & $11(18.6 \%)$ & $11.9(5.56-25.36)^{*}$ & $5.30(1.30-21.68)^{* *}$ & .020 \\
\hline
\end{tabular}

$* \mathrm{p}<0.05$, CI- 95\% (Confidence Interval), COD- crude odds ratio, AOD-adjusted odds ratio

** Remained statistically significant $(\mathrm{p}<0.05)$ in adjusted odds ratio

$\mathrm{P}$ value is for adjusted odd ratio

\section{Discussion}

Based on the findings of this study most of participant nurses $(148(76.7 \%))$ were in the age category of 21-30; which is in harmony with the study done in University of Gondar northern part of Ethiopia [39]. The possible reason for consistency of findings will be the similarity of study population, setting and area (Nurses, Hospital, Ethiopia) where as it is contrary to the study done in Assela Teaching and Referral Hospital, South East Ethiopia as most of participants are in the age category of 31-40 (69\%) [40].

In this study $64.9 \%$ of nurses had good knowledge about pain management consistent with the study done at University of Gondar Comprehensive Specialized Hospital, Northwest Ethiopia where $66.9 \%$ [41]. The study participants 
had good knowledge of pain management with a mean score of 7.14. The possible reason for the similarity between the current study and Northwest Ethiopia might be using a similar study design (cross- sectional) and comparable study population (nurses in specialized hospitals).

The result of this study was lower than the studies done in Uganda, Saudi Arabia, United Kingdom (UK), and Chicago, United States of America, 75\%, 87.5\%, 73.8\%, 74\%,[42] where these percentages of the study participants had good knowledge towards pain management respectively. The possible justification for this difference might be due to socioeconomic status, study setting, sample size, and use of different data collection tools. When comparing the sample size our study has larger sample size $(n=193)$ whereas in the study done in Uganda the sample size was lower $(n=67)$. The study setting was multicenter ( 6 federal hospitals) in this study, which resulted a difference But used the same questionnaire items of 16 knowledge questions. The socioeconomic difference may make a difference in the level of knowledge with Saudi Arabia, United Kingdom (UK), and Chicago, United States of America.

On the other hand the finding of the study was higher than that in the studies done in Mekelle, Ethiopia, 58.6\%, Zimbabwe, 35.5\% Iran, 46.6\%, Turkey, 38.2\%, Australia, 24\% and Malaysia, 25\% [43]. The sample size variation among the two studies could bring the discrepancy; Mekelle's study included 261 nurses, whereas the current study included 193 nurses. Likewise, the tool used in Mekelle's study is quite different, it was pain management for only children, in this study focused on adult critical ill patients. Moreover, differences in study setting, the difference in sample size, different tools used, and the difference in the outcome rating they used; might be the reason for the variation since the present study included nurses with master level of education these may relatively increase the knowledge status of the study participants.

Consequently more than half of participants have good practice $(56.5 \%)$ of pain management in present study which is in line with the study conducted in Amhara region northern part of Ethiopia (55.7\%) and a study conducted in Uganda (61.2\%). Towards the use of pain assessment tool at present study lesser nurses $(13.5 \%)$ do not implement the tools: this finding contradict to the study conducted in Asella Teaching and Referral Hospital, South East Ethiopia which is $94.23 \%$ of respondents do not use pain assessment tool. Similarly, in this study; about $89.1 \%$ of nurses document after assessing the patient condition. But in North India $82.69 \%$ of the participants have not documented findings after pain assessment.

Only $23.8 \%$ of nurses in this study use verbal rating scale contrary to the study conducted in North India; only $9 \%$ of nurses use verbal rating scale as a tool for assessing pain. Contrary to the study conducted in Uganda cancer institute; in this study most hospitals $(167 / 193,86.5 \%)$ have pain assessment tool but only $37.3 \%$ of nurses used the tool for assessing pain which is nearly similar to the above study [44] The possible differences may be socioeconomic status, study setting, sample size, and use of different data collection tools.

The study revealed that nurses who had Degree and above in nursing and nursing specialty has significant association in the multivariate logistic regression (AOR, 16.38; CI 95\%, 1.02-261.90); This finding in line with a study conducted in Turkey where nurses with an educational level of master's degree or higher and those who had taken a postgraduate course on pain management had a statistically significantly higher knowledge score than nurses with an associate degree $(p=0.001)$. Similarly the study is in line with the study conducted in Gondar Comprehensive Specialized Hospital, Northwest Ethiopia.

Received training related to ICU patient pain management for the last two years have a strong association with having adequate knowledge of pain management (AOR, $10.895 \%$ CI, 1.07-109.42) parallel to institutional based cross-sectional study conducted in Mekelle (35) and Amhara referral hospitals northern Ethiopia [45]. Nurses who had a work load have adequate knowledge of pain management (AOR, 8.8 (95\% CI; 1.45-53.39). This may be due to that nurses are overloaded with work that are part of their job so that will increase their knowledge. Nurses who have a good practice also have an adequate knowledge of pain management. This finding has some chicken egg dilemma that knowledge may be a predictor for practice or practice may be a predictor for knowledge of pain management.

Reading guideline occasionally as compared with reading always or frequently have 10 times more likely associated with poor knowledge of pain management (AOR, 10.11, CI $95 \%, 1.36-75.22)$ similar to this study in Mekelle northern part of Ethiopia (35). Nurse who have taken a pain management training have a better practice than those who haven't took a training on pain management (AOR, 19.21 4 CI 95\%, 48-18.95). Similar to this study; a cross-sectional study conducted in selected hospitals of Tigray, northern Ethiopia verified that nurses who are trained on pain management have good practice nineteen times more than those not trained (AOR, 19.95 (95\%CI; 3.03-130.9) [46]. According to this study nurse who haven't good knowledge or have inadequate knowledge have poor practice toward pain management (AOR, 5.30 95\% CI; 1.30-21.68) similar to the study conducted in Amhara region northern part of Ethiopia entitled 'Assessment of Nurses' Knowledge, Attitude, Practice and Associated Factors Towards Palliative Care".

\section{Limitation and Strength of the Study}

The study did not observe the actual practices of health care professionals' Management of pain in the ICU but relied on the self- report by the respondents as it is difficult to make an observation to each of participants. The other limitation was that this study was limited to federal hospitals in Addis Ababa city administration only (private health facilities and hospitals under Addis Ababa City Administration are not included in the study) as private hospitals are business oriented and admit non critical 
patients. It would have been possible to assess differences between regional and federal nurses' experiences as well as among different regional state nurses. The nature of crosssectional study design can only reflect experience of nurses at the time of assessment only, and therefore, a causal/temporal relationship cannot be established between Knowledge, Practice and its predictors.

\section{Conclusion}

The overall nurses' pain management knowledge level in federal hospitals of Addis Ababa is relatively high when compared with northern parts of Ethiopia (Mekelle, Gondar) but low when compared with developed and civilized countries (Uganda, Saudi Arabia, UK, and Chicago, USA). Among many factors contributed to the nurses' pain management knowledge in the multivariate logistic regression: work load, received training, frequency of reading guidelines, level of education, and Practice of nurses remained statistically significant in the multivariate analysis. Receiving a training related to ICU and having adequate knowledge of pain management were also significantly associated with practice of pain management. The nature of cross-sectional study design can only reflect experience of nurses at the time of assessment only, and therefore, a causal/temporal relationship cannot be established between Knowledge, Practice and its predictors. Again the study did not observe the actual practices of health care professionals' management of pain in the ICU and limited to federal hospitals in Addis Ababa city administration.

\section{Recommendation}

Federal hospitals in Addis Ababa would be better to improve the knowledge of health care personnel regarding pain management by providing adequate training that could enhance the nurse's knowledge in the area of pain management.

Trainings given for nurses by federal hospitals in Addis Ababa should focus on vital signs, severe pain, reliable potentiates of opioid analgesics, and dose ceiling effects.

Hospitals had better arrange a long-term training (formal education) as a post graduate program or Bsc. degree for diploma nurses that may help improve the knowledge on pain management.

Hospitals had better assign nurses on professional tasks as this increase their knowledge of pain management due to their exposure to different working areas and jobs.

Nurses had better read guidelines and standard protocols which matches their tasks assigned specifically to them and use pain assessment tools before pain management and hospitals should avail those materials for nurse's consumption.

Hospitals had better avail enough morphine and sedatives in their stock

Further research is needed to determine how best to break down current barriers to effective pain management.

\section{Ethical Considerations}

The study was conducted after getting ethical clearance from the research and ethical committee of St. Paul's hospital millennium medical college. Permission was taken from each hospital. The information collected from each study participants were used only for the research purpose and kept confidential. In addition to this to maintain confidentiality, study subjects were not identified by name.

\section{Competing Interests}

The authors declare that they have no competing interests.

\section{Acknowledgements}

Firstly, I would like to thank almighty GOD for keeping in health, giving strength \& courage to do this research proposal

I also wish to extend my gratitude to St. Paul's Hospital Millennium Medical College which gives me this chance to conduct this study.

I am grateful to my Advisors Mr. Solomon Oljira (BSc, $\mathrm{MSc}$ ) and Sr. Hana Abera (BSc, MSc) for their advice and guidance.

Last but not least, I wish to thank all those participants of this study and others who played a role in one way or another.

\section{References}

[1] Ababa A, Kassa H, Murugan R, Zewdu F, Hailu M, Woldeyohannes D. Assessment of knowledge, attitude and practice and associated factors towards palliative care among nurses working in selected hospitals, Addis Ababa, Ethiopia. BMC Palliat Care. 2014; 13 (1): 1-11.

[2] Bell L, Duffy A. Pain assessment and management in surgical nursing: a literature review. 2009; 18 (3): 153-6.

[3] Programs oh. brunner and suddarth's textbook of medicalsurgical nurasing. 1oth ed. Anason D, Ames W E, editor. 2016. $1-2227 \mathrm{p}$.

[4] Alzghoul BI, Azimah N, Abdullah C. Pain Management Practices by Nurses: An Application of the Knowledge, Attitude and Practices ( KAP) Model. 2016; 8 (6): 154-60.

[5] Goldberg DS, Mcgee SJ. Pain as a global public health priority. BMC Public Health [Internet]. 2011; 11 (1): 770.

[6] Kizza IIB, Sciences A. Nurses' Knowledge and Practices Related to Pain Assessment in Critically ill Patients at Mulago Hospital, Uganda. Dissertation. 2012; (November): 87.

[7] Vaillant F, Desjardins S. International Journal of Nursing Studies Implementation of the critical-care pain observation tool on pain assessment / management nursing practices in an intensive care unit with nonverbal critically ill adults: 2011; 48: 1495-504.

[8] Hosein A, Reza S, Kavosi A, Moghadam A, et al. Data in Brief Dataset on the nurses' knowledge, attitude and practice towards palliative care. $2019 ; 22: 319-25$. 
[9] Teixeira J, Durão M. Pain assessment in critically ill patients: an integrative literature review. Rev Enferm Ref. 2016; IV Série (10): 135-42.

[10] Georgiou E, Hadjibalassi M, Lambrinou E, Andreou P, Papathanassoglou EDE. The Impact of Pain Assessment on Critically Ill Patients' Outcomes: A Systematic Review. 2015; 2015.

[11] Yava A, Hatice Çicek, Nuran Tosun. Knowledge and Attitudes of Nurses about Pain Management in Turkey Berna Dizer, RN, PhD. Int J Caring Sci Sept. 2013; 6 (3): 494-505.

[12] Kizza I. Nurses' Knowledge and Practices Related to Pain Assessment in Critically ill Patients at Mulago Hospital, Uganda. Dissertation. 2012; (November): 87.

[13] Access O. We are IntechOpen, the world' s leading publisher of Open Access books Built by scientists, for scientists.

[14] Celis-Rodríguez E, Birchenall C, de la Cal MÁ, Castorena Arellano G, Hernández A, Ceraso D, et al. Clinical practice guidelines for evidence-based management of sedoanalgesia in critically ill adult patients. 2013; 37 (8): 519-74.

[15] Manwere A, Chipfuwa T, Mukwamba MM. iMedPub Journals Knowledge and Attitudes of Registered Nurses towards Pain Management of Adult Medical Patients: A Case of Bindura Hospital. 2015; 1-6.

[16] Kizza B, Muliira K. Nurses' pain assessment practices with critically ill adult patients. 2015; (Sessler 2009): 573-82.

[17] Herr K, McCaffery M, Coyne PJ, McCaffery M, Manworren R, Merkel S. Position Statement Pain Assessment in the Patient Unable to Self-Report: Position Statement with Clinical Practice Recommendations.

[18] Jeong IS, Park SM, Lee JM, Choi YJ, Lee J. Perceptions on pain management among Korean nurses in neonatal intensive care units. Asian Nurs Res 2014; 8 (4): 261-6.

[19] E M. June 2018 ababa, ethiopia. BMC Public Health. 2018; 12 (June): 1-29.

[20] Mondol S, Muhammad F, Chowdhury ABMA. Nurses' knowledge and practices related to pain assessment in critically ill patients in a selected private hospital in Bangladesh. 2018; 5 (10): 4219-24.

[21] Update E. Intensive Care Lunchtime Drop-in Sessions. 2018; 2018 (April): 1-44.

[22] Issa MR, Awajeh AM. iMedPub Journals Knowledge and Attitude about Pain and Pain Management among Critical Care Nurses in a Tertiary Hospital Abstract. 2017; 1-6.

[23] Techane t. knowledge, attitude and practice regarding cancer pain management among health care providers working at selected hospitals of addis ababa, ethiopia, 2018. 1-30 p.

[24] Abiru Neme GN and GB. Nurses' pain management competency and associated factors among nurses working in public hospitals, jimma zone, oromia regional state, southwest Ethiopia. 2018; 16: 1035-49.

[25] Kahsay DT. Emergency nurses' knowledge, attitude and perceived barriers regarding pain Management in ResourceLimited Settings: cross-sectional study. 2019; 1-13.

[26] Samuel Anteneh HK, Guadu. Assessment of Nurses' Knowledge, Attitude, Practice and Associated Factors
Towards Palliative Care: In the Case of Amhara Region Hospitals Assessment of Nurses ' Knowledge, Attitude, Practice and Associated. 2019.

[27] Sigakis MJG, Bittner EA. Ten Myths and Misconceptions Regarding Pain Management in the ICU. 2015; 43 (11).

[28] Salameh B. Nurses' knowledge regarding pain management in high acuity care units: A case study of Palestine.

[29] Report C. International Journal of Anesthesia and Evaluation of Knowledge and Attitudes by HealthCare Providers Regarding Pain in the ED and ICU. 2018; 2 (3): 19-32.

[30] Maria K, Evanthia V, Petros KA, Dimitris N. Assessment of Knowledge and Associated Factors towards Palliative Care among Greek Nurses. 2016; 3 (3).

[31] Wang H, Tsai Y. Nurses' knowledge and barriers regarding pain management in intensive care units. 2010; 3188-96.

[32] Albaqawi H, Maude P, Shawhan-akl L. Saudi Arabian Nurses' Knowledge and Attitudes Regarding Pain Management: Survey R 2016; 6 (December): 150-64.

[33] Yaqoob SH. Nurses' knowledge and attitudes toward pain assessment and management for adult sickle cell disease patients during sickling crisis. 2017; (May).

[34] Park J, Ph D, Kim JH. Assessment and Treatment of Pain in Adult Intensive Care Unit Patients. 2014; 29 (3): 147-59.

[35] Miftah R, Tilahun W, Fantahun A, Adulkadir S. Knowledge and factors associated with pain management for hospitalized children among nurses working in public hospitals in Mekelle City, North Ethiopia: cross sectional study. BMC Res Notes. $2017 ; 2-7$.

[36] Mohamed Naeem Badr. Critical care Nurses' Knowledge and Practices regarding Pain assessment and management at Cairo University Hospitals. 28-38.

[37] Al MM, Rn Q, Al MM, Rn K. Original Article Jordanian Nurses Knowledge and Attitude Regarding Pain Management. Pain Manag Nurs [Internet]. 2014; 15 (1): 220-8.

[38] Subhashini L, Vatsa M, Lodha R. Knowledge, Attitude and Practices Among Health Care Professionals Regarding Pain. 2009; 76 (June).

[39] Onwong IGM, Sciences H. NURSES' knowledge related to pain assessment for critically ill patients at a public sector. 2014.

[40] Wulff T. knowledge and clinical practice of nurses for adult post-operative orthopaedic pain management. 2012; (march).

[41] Furjanic M, Cooney A, Mccarthy B. Nurses' knowledge of pain and its management in older people. 2016; 28 (9): 32-7.

[42] AACPPO. Addis Ababa City Structure Plan. 2017; 1-10.

[43] Liyew B, Tilahun AD, Bayu NH. Knowledge and Attitude towards Pain Management among Nurses Working at University of Gondar Comprehensive Specialized Hospital, Northwest Ethiopia. 2020; 2020.

[44] Adem AO, Obsa MS, Worji TA. Assessments of health professionals' knowledge towards post-operative pain management in Asella Teaching and Referral Hospital, South East Ethiopia. 2017; 9 (November): 137-41. 
[45] Frank kiwanuka ronald masaba. Nurses' knowledge, attitude and practices regarding pain assessment among patients with cancer at Uganda Cancer Institute. 2018; 6 (2).
[46] Tanabe AP, Buschmann M. Emergency nurses' knowledge of pain management principles. 2000; (August): 299-305. 